\title{
A phase 2 clinical trial of the PPH Butterfly, a new device to 'turn off the tap' of Post-Partum Hemorrhage.
}

\author{
Andrew Weeks ${ }^{1}$, Caroline Cunningham ${ }^{2}$, Wendy Taylor ${ }^{3}$, Anna Rosala-Hallas ${ }^{1}$, Peter \\ Watt $^{4}$, Lucy Bryning ${ }^{5}$, Victory Ezeofor ${ }^{5}$, Liz Cregan ${ }^{2}$, Emma Hayden ${ }^{6}$, Dot Lambert ${ }^{1}$, \\ Carol Bedwell ${ }^{7}$, Steven Lane ${ }^{1}$, Tony Fisher ${ }^{4}$, Rhiannon Edwards ${ }^{5}$, and Dame Tina \\ Lavender ${ }^{7}$ \\ ${ }^{1}$ University of Liverpool \\ ${ }^{2}$ Liverpool Women's Hospital NHS Foundation Trust \\ ${ }^{3}$ The University of Manchester \\ ${ }^{4}$ Royal Liverpool and Broadgreen Hospitals NHS Trust \\ ${ }^{5}$ Bangor University \\ ${ }^{6}$ Expert by Experience \\ ${ }^{7}$ Liverpool School of Tropical Medicine
}

May 4, 2021

\begin{abstract}
Objective: To assess the acceptability, safety and efficacy of the PPH Butterfly, a new uterine compression device, in women with postpartum haemorrhage (PPH). Design: A phase two clinical device trial using matched historical controls, with accompanying grounded theory study. Setting: UK university consultant obstetric unit. Population: women with PPH after vaginal birth unresponsive to initial oxytocin therapy. Outcomes were compared to historical controls matched on blood loss, parity and type of birth. Methods: after oral consent, trained staff used the device in additional to normal care. Main Outcome Measures: The primary outcome was additional blood loss $>1000 \mathrm{mls}$. Qualitative interviews assessed device feasibility and acceptability. Results: Of the 57 recruits, two-thirds were primiparous and almost half had undergone operative birth. Two percent of recruited women had additional blood loss of over 1000mls compared to $8 \%$ of 113 controls (adjusted odds ratio $0.13,95 \%$ CI $(0.02$ to 1.09$))$. Women treated with the device received significantly more additional treatments and had higher rates of exclusive breast-feeding at discharge. There were no serious adverse events related to the device. In 47 interviews, participants, birth partners, clinicians and attending midwives viewed the device positively. Clinicians found it useful to stop blood loss and diagnose the source of bleeding. Conclusions: the PPH Butterfly is acceptable and may have clinical benefits: it is a promising device for PPH management. Funding: National Institute for Health Research invention for innovation (i4i) program (II-LA-0715-200008) Keywords: postpartum haemorrhage, childbirth, oxytocin, third stage of labour, uterine compression. Registration: prospective ISRCTN (15452399); www.isrctn.com/ISRCTN15452399
\end{abstract}

\section{Hosted file}

PPHB Main text + tables 29Apr2021.pdf available at https://authorea.com/users/384434/ articles/520761-a-phase-2-clinical-trial-of-the-pph-butterfly-a-new-device-to-turnoff-the-tap-of-post-partum-hemorrhage

\section{Hosted file}

PPHB Main Fig 1.pdf available at https://authorea.com/users/384434/articles/520761-a-phase2-clinical-trial-of-the-pph-butterfly-a-new-device-to-turn-off-the-tap-of-post-partum- 
hemorrhage

\section{Hosted file}

PPHB Main Fig 2.pdf available at https://authorea.com/users/384434/articles/520761-a-phase2-clinical-trial-of-the-pph-butterfly-a-new-device-to-turn-off-the-tap-of-post-partumhemorrhage

\section{Hosted file}

PPHB Main Fig S1.pdf available at https://authorea.com/users/384434/articles/520761-a-phase2-clinical-trial-of-the-pph-butterfly-a-new-device-to-turn-off-the-tap-of-post-partumhemorrhage 